\title{
EFFECTS OF THE MOLECULAR WEIGHT OF POLYCARBONATE ON THE MECHANICAL PROPERTIES OF CARBON FIBER REINFORCED POLYCARBONATE
}

\author{
KAZUTO TANAKA, KEISUKE TAKEMOTO, MASAHIRO SUZUE \& TSUTAO KATAYAMA \\ Department of Biomedical Engineering, Doshisha University, Japan
}

\begin{abstract}
Carbon Fiber Reinforced Thermoplastics (CFRTP) attract attention in the automotive industry because of their high specific strength and short production cycle. As Polycarbonate (PC) is excellent in terms of impact resistance, dimensional stability and heat resistance, as compared with other thermoplastic resins, it is expected to be used for CFRTP. Although PC with higher molecular weight has better impact resistance, due to its higher viscosity, it is difficult to impregnate into the continuous fibers. Therefore, the effects of molecular weight of PC on mechanical properties of Carbon Fiber Reinforced Polycarbonate (CF/PC) should be investigated. In this study, $\mathrm{CF} / \mathrm{PC}$ laminated composites were molded with two kinds of $\mathrm{PC}$ with different molecular weights, and their moldability and mechanical properties were evaluated. $\mathrm{CF} / \mathrm{PC}$ using $\mathrm{PC}$ with a high molecular weight tended to show a higher void fraction than that with a low molecular weight. $\mathrm{CF} / \mathrm{PC}$ using PC with a high molecular weight showed higher fiber/matrix interfacial shear strength in single fiber pull-out tests, and this result is considered to be the effect of the larger residual stress to the fiber, due to the larger difference in specific volume of PC with a higher molecular weight. CF/PC using PC with a high molecular weight showed higher interlaminar strength, bending strength, and absorbed energy in impact tests.

Keywords: carbon fiber, polycarbonate (PC), thermoplastics, CFRTP, molecular weight, fiber/matrix interfacial shear strength, pull-out test, residual stress, drop weight impact test.
\end{abstract}

\section{INTRODUCTION}

In recent years, environmental and energy issues resulting from the increase of the energy consumption become serious problems over the world. The energy consumption can be dramatically improved by using lightweight materials [1]. Therefore, Carbon Fiber Reinforced Plastics (CFRP) have received special attention in the automotive industry due to their high specific strength and high specific rigidity [2]. However, the curing time of the thermosetting plastics is timely leading to poor productivity and CFRP cannot generally be melted or reformed after the molding [3]. Carbon Fiber Reinforced Thermoplastics (CFRTP) have some advantages over conventional CFRP such as good impact resistance, short production cycle and high recyclability [4], [5].

As Polycarbonate (PC) is excellent in impact resistance that doesn't change even at low temperatures, dimensional stability and heat resistance as compared with other thermoplastic resins, it is expected to be applied for the matrix of CFRTP [6]. PC with higher molecular weight has better impact resistance [7]. This relationship is considered to be the effect of the easier molecular entanglements due to the longer molecular chain [8]. However, due to its higher viscosity it is difficult for PC with higher molecular weight to impregnate into the continuous fibers [6], [9]. Therefore, the effects of molecular weight of PC on mechanical properties of Carbon Fiber Reinforced Polycarbonate $(\mathrm{CF} / \mathrm{PC})$ should be investigated. In this study, CF/PC were molded with two kinds of $\mathrm{PC}$ with different molecular weights $(23,900$ and 15,200). To reveal the effects of molecular weight of PC on their moldability and their mechanical properties, the measurement of the void contents, single fiber pull-out tests, short beam bending tests, three-point bending tests and drop weight impact tests were conducted. 


\section{MATERIALS AND EXPERIMENTAL PROCEDURES}

\subsection{Materials and molding process}

Non-crimp fabric (NCF, $300 \mathrm{~g} / \mathrm{m}^{2},\left[0^{\circ} / 90^{\circ}\right]$, Toho Tenax, Japan), in which PAN-based carbon fibers are stitched together by polyester thread, was used as the reinforcement. PC of higher molecular weight (PC-2151; average molecular weight 23900, Charpy impact strength: $76 \mathrm{~kJ} / \mathrm{m}^{2}$, Teijin Ltd., Japan) and PC of lower molecular weight (L-1225LL; average molecular weight 15,200, Charpy impact strength: $3 \mathrm{~kJ} / \mathrm{m}^{2}$, Teijin Ltd., Japan) were used as the matrix. $\mathrm{CF} / \mathrm{PC}$ which were made from two kinds of $\mathrm{PC}$ were referred as $\mathrm{CF} / \mathrm{PC}(\mathrm{Mn}$ : 23,900) and CF/PC (Mn: 15,200) with each molecular weight, respectively.

CF/PC (Mn: 23,900) and CF/PC (Mn: 15,200) laminated composites were molded by a press machine (Satoh Machinery Works Co., Ltd., Japan) so as to be $18 \mathrm{~mm}$ in width, $280 \mathrm{~mm}$ in length, $2 \mathrm{~mm}$ in thickness and $\left[0^{\circ} / 90^{\circ}\right]_{3 \mathrm{~s}}$. Each molding condition is shown in Table 1. In order to evaluate the impregnation of the resin, the specimens were observed by a highresolution 3D X-ray microscope (Nano3DX, Rigaku, Japan).

\subsection{Single fiber pull-out test}

Single fiber pull-out tests were conducted to evaluate the interfacial strength between the matrix and fibers. The same carbon fibers used in NCF were used for single fiber pull-out tests. Fig. 1 shows the schematic drawing of preparation of the pull-out specimen. After a single fiber was glued to the tab with adhesive, the tab was attached to a micromanipulator. The resin was placed using the micromanipulator on the aluminum plate which was heated at molding temperature, and the single fiber was embedded to the matrix. Single fiber pullout tests were performed using an electro hydraulic servo controlled testing machine for micro materials (MMT-11N, Shimadzu Co., Japan). After chucking a specimen, the supporting part of the tab was cut and the single fiber pull-out test was conducted with a constant displacement rate of $1.7 \times 10-6 \mathrm{~m} / \mathrm{s}(0.1 \mathrm{~mm} / \mathrm{min})$. Fig. 2 shows the schematic drawing of the pull-out test. The interfacial shear strength was calculated by the following equation

$$
\tau=\frac{F_{\max }}{\pi d l},
$$

where $F_{\max }$ is maximum load, $d$ is fiber diameter and 1 is embedded fiber length.

The embedded fiber length 1 was measured for each pulled-out fiber observed by a scanning electron microscope (SEM, JSM-6390LT, JOEL Ltd, Japan).

\subsection{Short beam bending test}

To evaluate the interlaminar shear strength, short beam bending tests were conducted by a universal material testing machine (5566, Instron, U.S.A.), following the recommended testing procedures as described in JIS-K7057. The length and the width of specimen were $20 \mathrm{~mm}$ and $10 \mathrm{~mm}$, respectively. The span length was set for $10 \mathrm{~mm}$. The bending load was applied to the specimen at a displacement rate of $1.7 \times 10^{-5} \mathrm{~m} / \mathrm{s}(1.0 \mathrm{~mm} / \mathrm{min})$.

Table 1: Molding condition of the laminated composites.

\begin{tabular}{|c|c|c|c|}
\hline Maximum Temperature $\left[{ }^{\circ} \mathrm{C}\right]$ & Pressure $[\mathrm{MPa}]$ & Holding time $[\mathrm{s}]$ & $\mathrm{V}_{\mathrm{f}}[\%]$ \\
\hline 300 & 1 & 120 & 50 \\
\hline
\end{tabular}




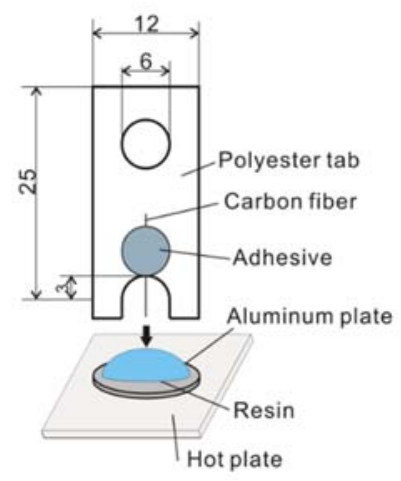

Figure 1: Preparation of pull-out specimen.

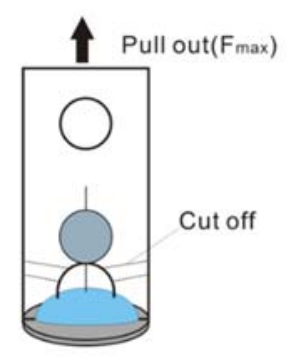

Figure 2: Pull-out specimen.

\subsection{Three-point bending test}

Three-point bending tests were conducted by a universal material testing machine, following the recommended testing procedures as described in JIS-K7074. The dimension of the specimens was set at $100 \times 15 \times 2 \mathrm{~mm}$. The specimen support span was $80 \mathrm{~mm}$. The cross-head displacement rate was set for $1.7 \times 10^{-5} \mathrm{~m} / \mathrm{s}(5 \mathrm{~mm} / \mathrm{min})$.

\subsection{Drop weight impact test}

Drop weight impact tests were conducted by using an instrumented drop weight impact test machine (IITM-18, Yonekura Co., Japan). The specimen configuration was a regular octagon shape of $25 \mathrm{~mm}$ in the side length. The specimen was fixed by using a suppression board with a hole of $40 \mathrm{~mm}$ in the diameter, and a hemisphere of $10 \mathrm{~mm}$ in the diameter was used as the striker. In order to apply a $7 \mathrm{~J}$ per $1 \mathrm{~mm}$ in the specimen thickness, the height of the drop weight was adjusted.

\section{RESULTS AND DISCUSSION}

\subsection{Evaluation of impregnation}

Fig. 3 shows the void contents of CF/PC(Mn:23900) and CF/PC(Mn:15200) which were obtained by the high-resolution 3D X-ray microscope. The void content of $\mathrm{CF} / \mathrm{PC}(\mathrm{Mn}$ : $23,900)$ and $\mathrm{CF} / \mathrm{PC}(\mathrm{Mn}: 15,200)$ were $4.1 \%$ and $2.8 \%$, respectively. CF/PC (Mn: 23,900) tended to have worse impregnating ability than $\mathrm{CF} / \mathrm{PC}(\mathrm{Mn}: 15,200)$ due to higher viscosity. 


\subsection{Single fiber pull-out test}

Fig. 4 shows the relationship between embedded fiber length and maximum load of pull-out tests (the interfacial fracture load is plotted in the left, and the fiber fracture load is plotted in the right). Fig. 5 shows the interfacial shear strengths of CF/PC (Mn: 23,900) and CF/PC (Mn: 15,200). The interfacial shear strengths of CF/PC (Mn: 23,900) and CF/PC (Mn: $15,200)$ were $64.1 \mathrm{MPa}$ and $42.3 \mathrm{MPa}$, respectively. The residual stress was reported to be caused by the thermal shrinkage from the change of the specific volume [10]. Generally, the bigger molecular weight has bigger thermal shrinkage [11]. The interfacial shear strength decreases by the reduction of the residual stress in the radial direction [12]. The reason for the higher interfacial shear strength of CF/PC (Mn: 23,900) than CF/PC (Mn: 15,200) is considered to be the thermal shrinkage in preparation of the pull-out specimens.

\subsection{Short beam bending test}

Fig. 6 shows the interlaminar shear strengths of CF/PC (Mn: 23,900) and CF/PC (Mn: 15,200). The interlaminar shear strengths of CF/PC (Mn: 23,900) and CF/PC (Mn: 15,200) were 42.6 MPa and 33.7 MPa, respectively. CF/PC (Mn: 23,900) showed higher interlaminar shear strength than CF/PC (Mn: 15,200). Fig. 7 shows side view after short beam bending test for each specimen. Both specimens had the delamination between the $90^{\circ}$ and $90^{\circ}$ layers in the middle of the thickness. Fig. 8 shows the fracture surface of each specimen observed by SEM. For CF/PC (Mn:23900), most of the fibers were covered with resin and larger deformation of resin were observed. $\mathrm{CF} / \mathrm{PC}(\mathrm{Mn}: 23,900)$, which had higher fiber/matrix interfacial strength, had higher interlaminar shear strength than CF/PC (Mn: 15,200).

\subsection{Three-point bending test}

Fig. 9 shows stress-strain curves of CF/PC (Mn: 23,900) and CF/PC (Mn: 15,200) for threepoint bending test. Fig. 10 shows bending strengths and moduli of each specimen. While there is no significant difference in bending modulus between $\mathrm{CF} / \mathrm{PC}(\mathrm{Mn}: 23,900)$ and $\mathrm{CF} / \mathrm{PC}$ (Mn: 15,200), CF/PC (Mn: 23,900) showed higher bending strength than CF/PC (Mn: 15,200). Figs. 11 and 12 show the side view during the three-point bending tests. For CF/PC (Mn: 23900), the initial crack started at the bottom of the indenter in the compression side and the crack propagation to the thickness direction. On the contrary for CF/PC (Mn: 15,200), the initial crack started at the bottom of the indenter in the compression side and the crack propagation to the horizontal direction.

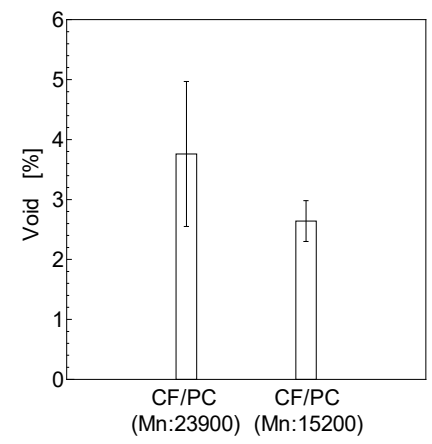

Figure 3: Void content of CF/PC. 


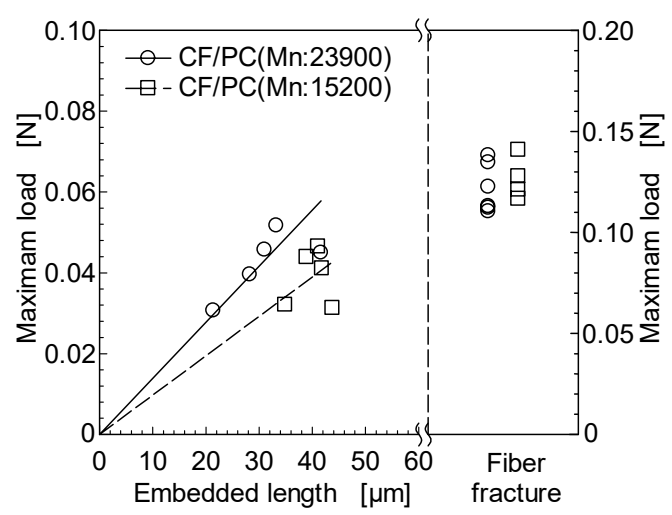

Figure 4: The relationship between embedded fiber length and maximum load of pull-out tests (the interfacial fracture load is plotted in the left, and the fiber fracture load is plotted in the right).

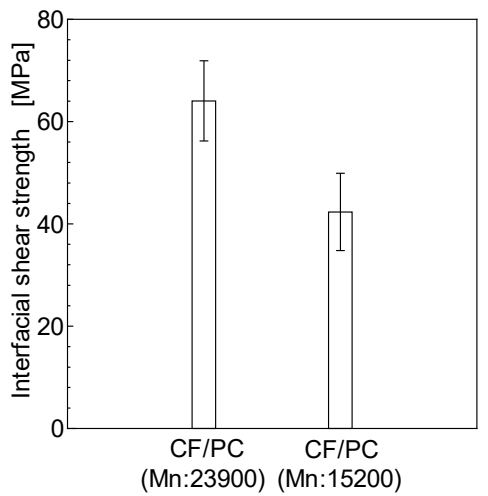

Figure 5: Interfacial shear strength of $\mathrm{CF} / \mathrm{PC}$.

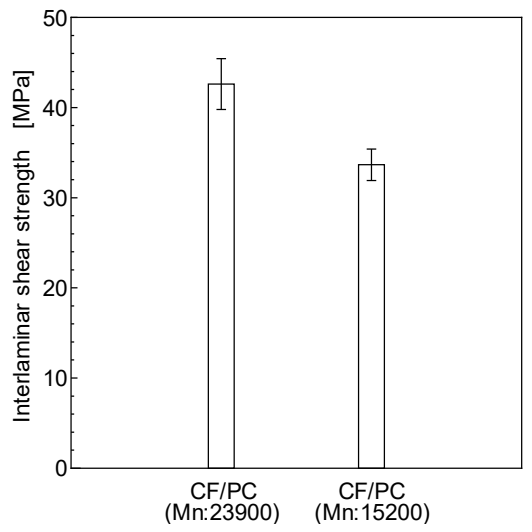

Figure 6: Interlaminar shear strength of $\mathrm{CF} / \mathrm{PC}$. 


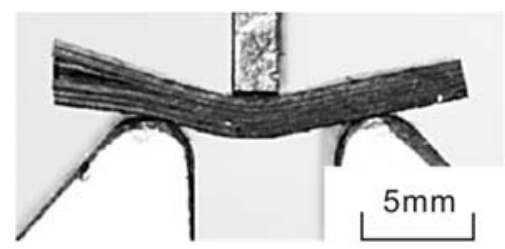

(a): CF/PC (Mn: 23,900)

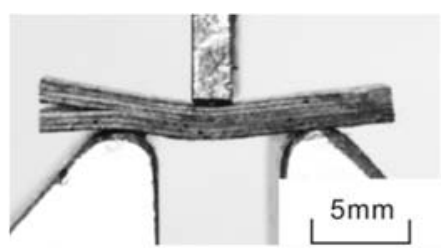

(b): CF/PC (Mn: 15,200)

Figure 7: Side view of the specimens for short beam bending test.

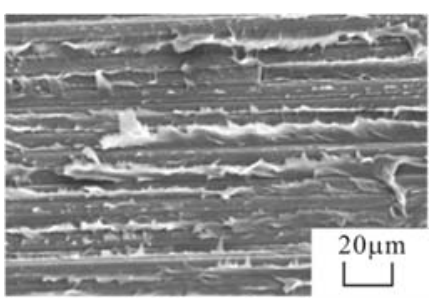

(a): CF/PC (Mn: 23,900)

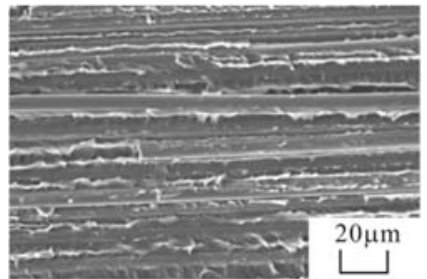

(b): CF/PC (Mn: 15,200)

Figure 8: Fracture surfaces for short beam bending test.

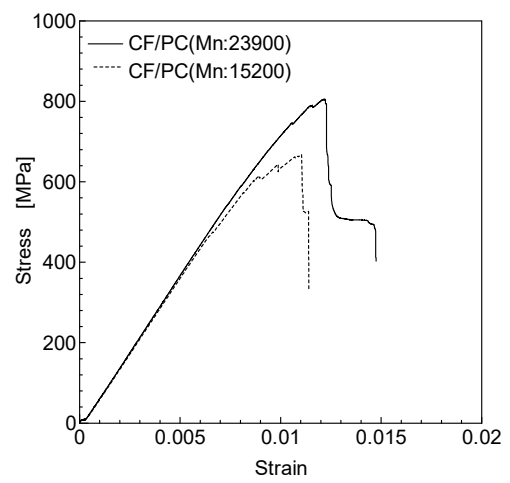

Figure 9: Stress-strain curves of CF/PC for three-point bending test.
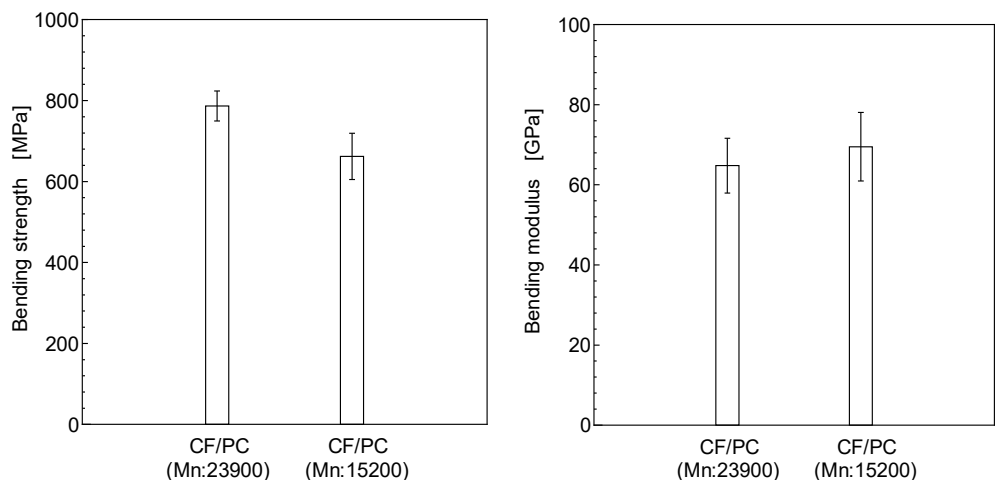

Figure 10: Bending strength and modulus of $\mathrm{CF} / \mathrm{PC}$. 


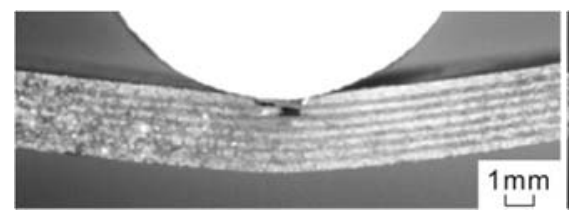

(a): Initial crack

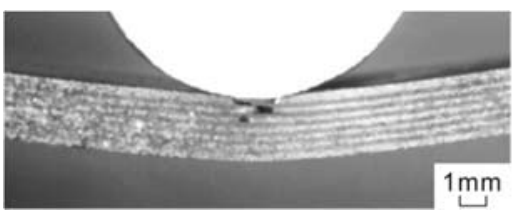

(b): In the middle of fracture $(\varepsilon=0.012 \%)$

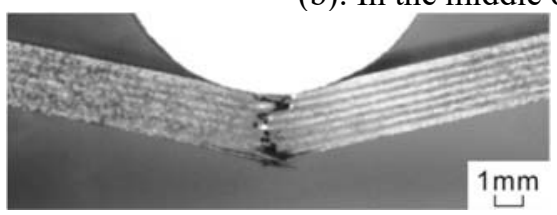

(c): After fracture

Figure 11: $\mathrm{CF} / \mathrm{PC}(\mathrm{Mn}: 23,900)$ of bending test.

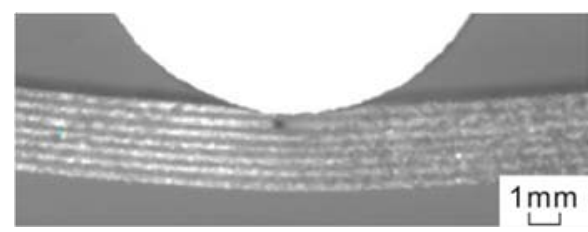

(a): Initial crack

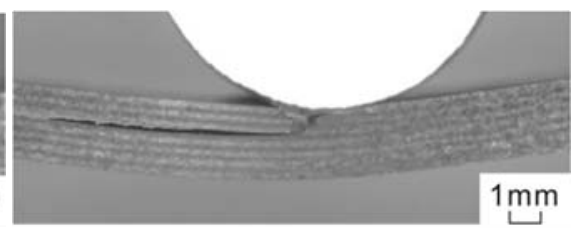

(b): In the middle of fracture $(\varepsilon=0.011 \%)$

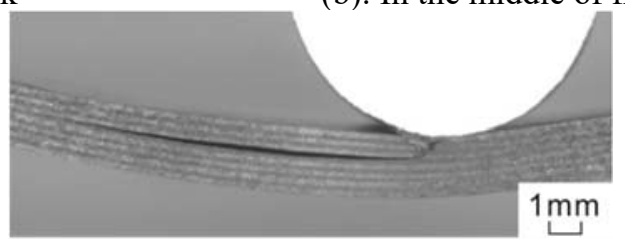

(c): After fracture

Figure 12: $\mathrm{CF} / \mathrm{PC}(\mathrm{Mn}: 15200)$ of bending test.

\subsection{Drop weight impact test}

Fig. 13 shows the load-displacement curves of CF/PC (Mn: 23,900) and CF/PC (Mn: 15,200) for drop weight impact test. Fig. 14 shows the absorbed energy-displacement curves of each specimen. CF/PC (Mn: 23,900) showed higher load and absorbed energy than CF/PC (Mn: 15,200). Fig. 15 shows the back side of the specimen after drop weight impact test. Though the striker pierced both specimens, $\mathrm{CF} / \mathrm{PC}(\mathrm{Mn}: 23,900)$ had smaller delamination than $\mathrm{CF} / \mathrm{PC}$ (Mn: 15,200). It is reported that smaller delamination showed higher resin toughness [13] and higher interfacial shear strength [14], [15]. As the Charpy impact strengths of PC (Mn: 23,900) and PC (Mn: 15,200) are $76 \mathrm{~kJ} / \mathrm{m}^{2}$ and $3 \mathrm{~kJ} / \mathrm{m}^{2}$, respectively, CF/PC (Mn: $23,900)$ is considered to have higher resin toughness than CF/PC (Mn: 15,200). CF/PC (Mn: 23,900), which have higher resin toughness and higher interfacial shear strength, had higher interlaminar shear strength, bending strength and absorbed energy and smaller delamination than CF/PC (Mn: 15,200). CF/PC (Mn: 23,900) showed more superior mechanical properties than $\mathrm{CF} / \mathrm{PC}(\mathrm{Mn}: 15,200)$, which suggests that $\mathrm{PC}(\mathrm{Mn}: 23,900)$ is more suitable for the matrix of $\mathrm{CF} / \mathrm{PC}$ than $\mathrm{PC}(\mathrm{Mn}: 15,200)$. 


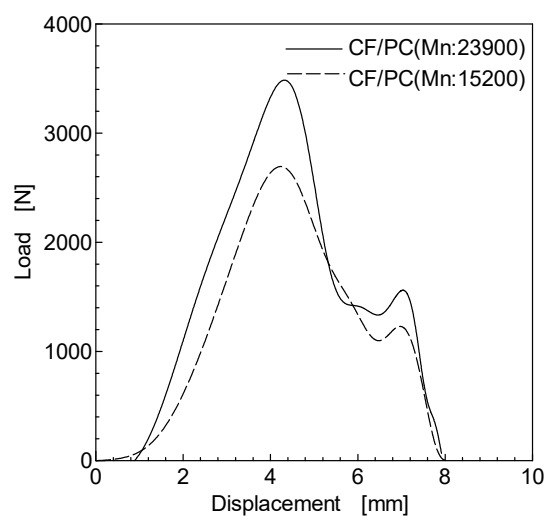

Figure 13: Load-displacement curve of drop weight impact test.

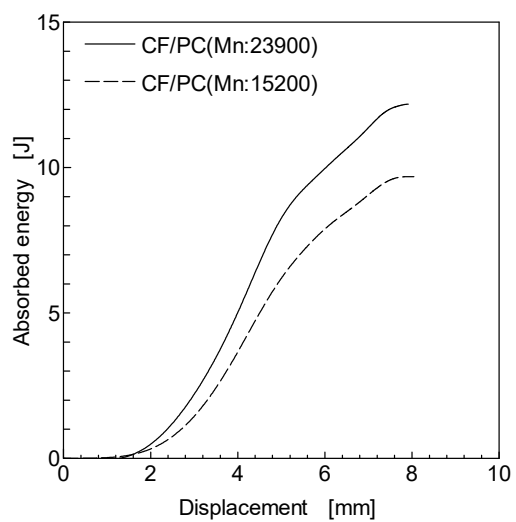

Figure 14: Absorbed energy-displacement curve of drop weight impact test.

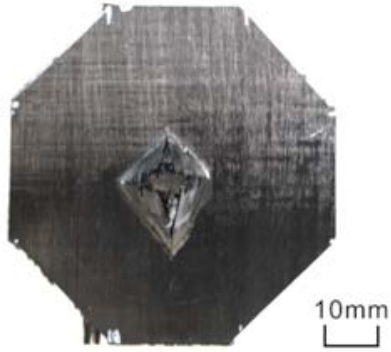

(a): $\mathrm{CF} / \mathrm{PC}(\mathrm{Mn}: 23900)$

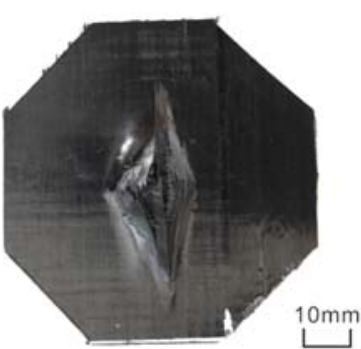

(b): $\mathrm{CF} / \mathrm{PC}(\mathrm{Mn}: 15200)$

Figure 15: Back side of specimens after drop weight impact test.

\section{CONCLUSIONS}

Carbon Fiber Reinforced Polycarbonate (CF/PC) laminated composites were molded with two kinds of PC with different molecular weights and their moldability and their mechanical properties were evaluated. The investigation yielded the following conclusions: 
1. $\mathrm{CF} / \mathrm{PC}$ (Mn: 23,900) tended to show higher void fraction than CF/PC (Mn: 15,200).

2. $\mathrm{CF} / \mathrm{PC}(\mathrm{Mn}: 23,900)$ showed higher fiber/matrix interfacial shear strength in single fiber pull-out tests. This result is considered to be the effect of the larger residual stress to the fiber due to the larger difference in specific volume of PC (Mn: 23,900).

3. CF/PC (Mn: 23,900) showed higher interlaminar strength, bending strength and absorbed energy in impact tests. This suggests that PC (Mn: 23,900) is more suitable for the matrix of CF/PC than PC (Mn: 15,200).

\section{REFERENCES}

[1] Shimizu, N., Development Status of Carbon Fiber Reinforced Plastics. Laser Review, 38(8), pp. 603-608, 2010.

[2] Plastics and Polymer Composites Technology Roadmap for Automotive Markets, Plastics Division. American Chemistry Council, pp. 1-5, 2014.

[3] Matsutsuka, N., Takahashi, J., Zushi, H., Osawa, I. \& Uzawa, K., Evaluation of Recycled CFRTP for Mass Production Applications. The Ninth Japan International SAMPE symposium, (29), pp. 50-55, 2005.

[4] Galoone, A., Ariante, M., Fusco, G., Flores, F.F., Bizzarro, G., Zinno, A. \& Prota, A., Thermoplastic Composite Structure for Mass Transit Vehicle: Design, computational engineering and experimental validation. 15th European Conference on Composite Materials, pp. 24-28, 2012.

[5] Ning, H., Vaidya, U., Janowski, G.M. \& Husman, G., Design, Manufacture and Analysis of a Thermoplastic Composite Frame Structure for Mass Transit. Composite Structure, 80, pp. 105-116, 2007.

[6] Takeda, S. \& Nagao, Y., Evaluation of Tensile and Impact Characteristics for Carbon Fiber Reinforced Polycarbonates. The Japan Society for Aeronautical and Space Sciences, 50, pp. 94-96, 2008.

[7] Soma, H., Nishitsuji, S. \& Inoue, T., Molecular Weight Dependence in A Relaxation Phenomenon at Glassy State: Physical aging of polycarbonate. Polymer, 53(4), pp. 895896, 2012.

[8] Honma, S., Practical Use Strength and Durability of Plastic (2). Industrial Investigation Committee, 54(11), pp. 95-102, 2003.

[9] Sakai, T., Takeda, S., Nagao, Y. \& Toda, S., Low-cost Molding Method of Carbon Fiber Reinforced Polycarbonates. Japan Society for Composite Materials, 33, pp. 53-54, 2008.

[10] Honma, S., Plactical Use Strength and Durability of Plastic (11). Industrial Investigation Committee, 55(8), pp. 87-97, 2004.

[11] Fox, T.G., Loshaek, S., Rohm \& Haas Company, Influence of Molecular Weight and Degree of Crosslinking on The Specific Volume and Glass Temperature of Polymers. Journal of Polymer Science, 15, pp. 371-390, 1955.

[12] Tanaka, K., Hosoo, N., Katayama, T., Noguchi, Y. \& Izui, K., Effect of Temperature on The Fiber/matrix Interfacial Strength of Carbon Fiber Reinforced Polyamide Model Composites. Mechanical Engineering Journal, 3(6), pp. 16-158, 2016.

[13] Miyairi, H., An Introduction to Composite Materials, Shokabo: Japan, p. 237, 1997.

[14] Nagai, M., Fukushi, K., Kamata, Y. \& Kadotani, K., Relation between Glass Materials and Mechanical Strengths on High Density GFRP for Cryogenic Use. Journal of Cryogenics and Superconductivity Society of Japan, 22(3), pp. 200-206, 1987.

[15] Kamiya, A., Nakano, K., Moribe, S., Imura, T. \& Ichikawa, H., Mechanical Properties of Unidirectional HI-NICALON Fiber-Reinforced Si3N4 Matrix Composites. Journal of the Ceramic Society of Japan, 102(1190), pp. 957-960, 1994. 